\title{
PROCESSOS TRADUTÓRIOS ENTRE OS KAXINAWÁ: A EXPERIÊNCIA DE UM CANTADOR
}

Rafael Fares*

RESUMO: Neste artigo pretende-se apresentar alguns processos tradutórios desenvolvidos, conjuntamente com parceiros não-indígenas, pelo pesquisador e cantador Ibã Kaxinawá, com o intuito de atualizar aspectos de sua tradição cultural. Dentre estes processos estão as traduções interlinguísticas e as traduções intersemióticas, ambas intimamente relacionadas com a narrativa do Nix Pae - o espiríto da floresta.

PALAVRAS-CHAVE: Tradução; Povo Kaxinawá; Cantos Indígenas; Poéticas extra-ocidentais

\author{
* rafaelotavio@hotmail.com \\ Doutorando em teoria da literatura e mestre em \\ literatura brasileira pela UFMG.
}

RÉSUMÉ: Dans cet article, nous avons l'intention de présenter certains procédés de traduction développés conjointement avec des partenaires non-indigènes, par le chercheur et chanteur Kaxinawá lbã, afin de mettre à jour aspects de leur tradition culturelle. Parmi ces procédés sont des traductions interlinguisticas et des traductions intersémiotiques, tous deux étroitement liés à la narration de Nixi Pae - L'esprit de la forêt.

MOTS-CLÉ: Traduction; Peuple Kaxinawá; Chants indigènes; Poétiques extra-occidentaux. 
1. O projeto constitui-se de vários seminários entre indígenas e não-indigenas de todo o Brasil, debatendo temas como educação, línguas indígenas, tradução e tradição, em Minas Gerais e no Acre.

2. Os Kaxinawá são aproximadamente 8.000 pessoas vivem na divisa do Brasil com Peru. A língua falada pelo grupo faz parte do tronco linguístico pano.

3. Atualmente o termo tem sido usado ao invés de alucinógeno, um esforço para tentar separar o conceito de droga, que danifica o organismo, para o de estado visionário. O filósofo Gilles Deleuze usa o termo delírio no sentindo que afirmamos aqui. Sentido de devir.

4. O texto "Miração" foi apresentado no projeto Janela da Dramaturgia 2013. O projeto faz leituras para público de novos textos teatrais.

5. Davi Yanomami tem se destacado como uma das grandes lideranças indígenas no Brasil e no mundo. Seu povo tambem possui diversos cantos que ele relaciona com o xamanismo e a visão de mundo do seu povo. Davi esteve em Belo Horizonte nos dias 4,5 e 6, de novembro de 2013 , realizando uma serie de conferencias no IEAT - Instituto de Estudos Avançados Transdiciplinares da UFMG
Fim último da literatura: pôr em evidência no delírio essa criação de uma saúde, ou essa invenção de um povo, isto é, uma possibilidade de vida. Escrever por esse povo que falta... ("por" significa "em intenção de" e não "em lugar de").

Crítica e Clínica - Gilles Deleuze e Félix Guattari

Era a minha primeira viagem ao Acre. Eu estava participando dos Diálogos Interculturais, projeto promovido pela Professora Maria Inês de Almeida e pelo programa Cultura e Pensamento do Ministério da Cultura ${ }^{1}$. O objetivo do evento era proporcionar trocas diversas sobre os conhecimentos tradicionais e acadêmicos, por isso participavam professores e pesquisadores de várias áreas e indígenas de diferentes etnias. Naquela vivência conheci Ibã Kaxinawá ${ }^{2}$ e tomei, com o acompanhamento dele, o chá conhecido como ayahuasca Foi uma experiência de revelações e visões enteógenas ${ }^{3}$, o que vim a saber se chama mirar ou, como substantivo, miração. Além de minhas várias experiências sensoriais, que transformei em texto para teatro ${ }^{4}$, naquela noite conheci diversos pensadores e cantores, de variados povos indígenas, como, por exemplo, Davi Yanomami ${ }^{5}$.

$\mathrm{Na}$ ocasião escutei, pela primeira vez, o canto Kaxinawá na voz de Ibã. Foi uma experiência fascinante, pois trata-se de música extremante bela, além de possuir uma construção diferente em relação às canções da chamada música ocidental.
Um canto repetitivo e melodioso, com articulações vocais próprias e um uso muito singular da respiração e do sopro, que normalmente fecham as canções. Como em diversas outras tradições indígenas, nesses cantos são contadas narrativas míticas que, em suas traduções para o português, cada vez mais comuns, abrem possibilidades de conhecimento destas culturas para o falante de português. Como nos diz Pedro Cesarino, tradutor dos cantos da mitologia Marubo:

Cada língua implica um mundo, uma construção de pensamento, uma estética e uma produção ritual. Se somarmos a isso o fato de que esses mundos são bastante distintos daqueles que deram origem às formas ocidentais de pensamento, então percebemos a distância a ser percorrida para que haja uma compreensão mais efetiva dos referencias intelectuais e criativos indígenas. Daí a necessidade de uma aproximação tradutória, que busca uma compreensão mais afinada de tais singulares poéticas. ${ }^{6}$

Ao som da voz potente do cantador, eu, que em estado de vigília me encontrava deitado numa rede, vi diversas imagens cobrindo o corpo das coisas, desenhos gráficos que eu tinha observado nas pinturas e tecidos dos Kaxinawá do evento. Quando Ibã terminou com o canto adequado sua sessão de cantoria, despertei do estado em que me encontrava e pudemos conversar sobre o que se passou. Perguntei a ele o que eram os desenhos que eu tinha visto e ele me explicou que eram os Kenes.
6. CESARINO. Quando a Terra deixou de falar, p.7
EM TESE
BELO HORIZONTE
v. 19
N. 3
SET.-DEz. 2013 FARES. Processos tradutórios entre os Kaxinawá
P. $137-147$

Tradução e Edição 
7. Em 2000, a editora da UFMG publicou o livro Shenipapu Miyui: história do antigos. Feito com os professores indigenas Kaxin
entre eles Joaquim Mana.

8. Palestra proferida no dia 17/06/2013 no seminário de abertura da exposição Mira Artes Visuais Contemporâneas dos Povos Indígenas.

9. Kaxinawá é o nome dado pelos não-indígenas.
Os Kenes são como motivos gráficos, iconografias que são escritas pelos Kaxinawá em diversos suportes, mas principalmente no corpo e no tecido. Os Kenes são encontrados em todos os povos da família lingüística Pano e podemos pensá-los como um tipo de escrita ideogramática. Os sinais gráficos não se equivalem ao alfabeto: sintetizam idéias, suscitam imagens e movimento, eles não representam sons da fala. No livro Nuku Kene Xarabu (Nossos desenhos tradicionais) ${ }^{7}$, fruto da pesquisa de Joaquim Naná Kaxinawá, são catalogados 62 motivos em tecidos encontrados em diversas aldeias.

Ibã também contou que umas das práticas para ser um conhecedor Kaxinawá é acordar depois de sua miração desenhar o que foi visto: "É um estudo, assim nascem os desenhos" disse ele. Ou como nos conta a antropóloga Els Lagrou sobre os conselhos que dão os donos de uma sessão de ayahuasca: "tem que ficar dentro do desenho, para não se perder na visão. $\mathrm{O}$ desenho funciona aqui como um mapa, que o espírito do olho do jovem tem que visualizar e seguir no mundo dos seres e imagens" ${ }^{\prime \prime}$.

Para acompanharmos de maneira mais enriquecedora o desenvolvimento destes desenhos com a cultura Kaxinawá e as traduções que vamos tratar aqui, é importante que entendamos a relação destes desenhos com uma narrativa mítica fundamental para os Kaxinawá: a história do Nixi Pae. No Livro Nixi Pae - O espírito da floresta, os Kaxinawá, conhecidos também como Huni Kuin ${ }^{9}$, nos contam uma história de um indígena que vai tentar caçar uma anta. Ele se esconde em uma moita e descobre que a anta faz um movimento com três frutas de jenipapo em frente ao rio e de lá sai uma jibóia-moça que tem relações sexuais com a anta. O homem, vendo aquilo, espera a anta ir e faz a mesma coisa. A moça-jibóia aparece e ele então passa a namorá-la. A mulher-jibóia o leva para baixo das águas do rio, lugar onde vivem seus parentes. Lá, o homem conhece o cipó, que dá a ele uma miração muito forte. Ele vê seus parentes-jibóia comendo-o. Durante esta miração, ele grita muito sobre sua vida e faz com que seus parentes-jibóia fiquem com desconfiança dele, fato que o deixa triste e desolado. Aparece-lhe, então, uma mulher que lhe ensina o caminho de volta ao seu mundo. Ao retornar, encontra um cunhado e lhe conta a história que viveu com a mulher-jibóia. Seus filhos-jibóia ficam preocupados e o filho mais novo procura e encontra o pai. Ele chama seus irmãos e sua mãe e todos mordem o pai. Este é engolido até a cintura e grita aos seus parentes, que conseguem tirar as jibóias dele. Com o corpo todo mole e doente, antes de morrer, explica para seu cunhado:

Quando eu morrer me enterra, passando seis meses pode me procurar na minha sepultura. Na parte direita vou virar cipó, na parte esquerda vou virar rainha. Tira o cipó, corta uma palma de comprido, bate com um pedaço de pau, tira a casca, bota água junto com a folha, pode cozinhar e depois cantando, eu fico dentro do cipó explicando pra você. ${ }^{10}$
10. KAXINAWÁ. Nixi pae - O espírito da floresta, p. 34.
EM TESE
BELO HORIZONTE
v. 19
N. 3
SET.-DEz. 2013 FARES. Processos tradutórios entre os Kaxinawá
p. $137-147$

Tradução e Edição 
12. CASTRO. A inconstância da alma selvagem, p. 358.
O chá do cipó, descrito acima, é uma bebida fundamental para todos os rituais e vários processos de conhecimento dos Huni Kuin. Eles tomam o cipó para através de experiências visionárias, mirarem sobre algo que desejam, para aprenderem novas histórias ou desenhos para serem utilizados nos artesanatos, nas pinturas corporais e demais objetos que vão construir.

Eles tomam ayahuasca para visitarem o mundo dos espí ritos, adquirem pontos de vista dos seres, animais, plantas e minerais que são também espíritos. É o que o antropólogo Vivieros de Castro chama de "qualidade perspectiva" do pensamento ameríndio. Sua reflexão parte da premissa de que o modo como os seres humanos vêem os animais e outros seres espirituais, é diferente do modo como esses seres vêem os humanos. Diz ele:

Os animais predadores e os espíritos, entretanto, vêem os humanos como animais de presa, ao passo que os animais de presa vêem os humanos como espíritos ou como animais predadores. [...] Eles se apreendem como, ou se tornam, antropomorfos quando estão em suas próprias casas ou aldeias, e experimentam seus próprios hábitos e características sob a espécie de cultura: vêem seu alimento como alimento humano (os jaguares vêem o sangue como cauim, os mortos vêem os grilos como peixes, os urubus vêem os vermes da carne podre como peixe assado etc.), adornos corporais (pelagem, plumas, garras, bicos, etc.) como adornos ou instrumentos culturais, seu sistema social como or- ganizado identicamente às instituições humanas (com chefes, xamãs, ritos, regras de casamentos etc.). ${ }^{11}$

Neste sentido, não se adquire um ponto de vista ao olhar de outro ângulo, mas ao poder viver em intensidade outro corpo, outra natureza, potência estimulada pela ingestão do cipó. É através do xamã, ou pajé, experiente de experiências com a bebida, que uma comunidade indígena poderá conhecer outros pontos de vista:

O xamanismo amazônico pode ser definido como habilidade manifesta por certos indivíduos de cruzar deliberadamente as barreiras corporais e adotar a perspectiva de subjetividades alo-especificas, de modo a administrar as relações entre estas e os humanos. Vendo os seres não-humanos como estes se vêem (como humanos), os \xamãs são capazes de assumir o papel de interlocutores ativos no diálogo transespecífico; sobretudo, eles são capazes de voltar para contar a história, algo que os leigos dificilmente podem fazer. $\mathrm{O}$ encontro ou o intercâmbio de perspectivas é um processo perigoso, e uma arte política - uma diplomacia. Se o "multiculturalismo" ocidental é o relativismo como política pública, o perspectivismo xamânico é o multinaturalismo como política pública ${ }^{12}$

Imagens que como perspectivas, novos pontos de vista, são devires, no sentido proposto por Gilles Deleuze e Felix Gattari. Elas não se relacionam necessariamente com a representação
11. CASTRO. A inconstância da alma selvagem, p.350.
EM TESE
BELO HORIZONTE
v. 19
N. 3
SET.-DEZ. 2013
FARES. Processos tradutórios entre os Kaxinawá
P. $137-147$

Tradução e Edição 
13. GUIMARÃES. A força da letra, p. 144.

14. DELEUZE. Mil Platôs $4-$ capitalismo e esquizofrenia, p. 19

15. BLANCHOT apud GUIMARÃES. $O$ espaço literário, p. 144.

16. GUIMARÃES. A força da letra, p. 144.

17. LAGROU. A fluidez da forma, p. 71. no sentido clássico que "faz da imagem um termo segundo em relação ao objeto que ela representa"13 As mirações não são simulacros de algo "real", por isso é tão interessante o que formula Deleuze e Gattari: "o devir não produz outra coisa se não ele próprio. É uma falsa alternativa que nos faz dizer: ou imitamos ou não somos" ${ }^{14}$. É a experiência que Blanchot denomina "viver um evento em imagem" ${ }^{15}$, e que esses eventos fazem parte do significante, o que "implica não o controle ou o apaziguamento da distância entre nós e o real, mas nos deixarmos atrair para uma região na qual aquilo que nos detém e fascina é a distância mesma entre nós e o real”"16.

As histórias dos Kaxinawás não são, portanto, histórias do passado, com valor de fábula. A jibóia é quem ensina histórias e cantos para os Huni Kuin para serem praticados, com vivacidade, no momento presente, sempre sendo atualizados em quantos devires quantos forem as experiências de miração. Além disso, os motivos gráficos têm sua formalização e regra de composição pelo desenho da pele da cobra, como assinala a antropóloga Els Lagrou:

Resumindo, podemos dizer que o yuxibu [espírito] da jibóia/ sucuri deu ao homem o conhecimento tanto de preparar quanto de tomar a bebida, o conhecimento de produzir visões, e às mulheres o conhecimento de produzir e gerar desenhos. Todos os desenhos possíveis se encontram virtualmente na pele da cobra, onde um desenho pode ser transformado em outro seguindo certas regras de composição. ${ }^{17}$
No documentário Huni Meka, um dos vídeos-documentários produzidos por Zezinho Huni Kuin, cineasta indígena formado pelo "Vídeo nas aldeias"18, os Huni Kuin discutem de quem seria o direito autoral, no caso da gravação de um $\mathrm{CD}$, de músicas do seu povo, já que, para eles, é a jibóia a autora dos cantos.

\section{A TRADUÇÃo COMO UM PROCESSO}

Já são 7 anos transcorridos desde o dia narrado acima, de meu primeiro encontro com Ibã. Tanto Ibã Kaxinawá, conjuntamente com seu povo e a universidade do Acre, continuou sua pesquisa, quanto meus colegas de universidade e eu continuamos a nossa, mantendo contato periodicamente. Ibã, como estudante da UFAC de Rio Branco, passou a frequentar a UFMG como pesquisador do Núcleo Literaterras ${ }^{19}$.

Atualmente desenvolve, em seu intercâmbio com o Núcleo um projeto de tradução de cantos ligados a processos de cura, pesquisa que ele chama de Ervas Perfumosas da Floresta. Vale ressaltar que a concepção de saúde para os Kaxinawá é bem diferente da tradição ocidental. É digno de nota a publicação feita pelo Núcleo Literaterras, em parceria com a Associação Filmes de Quintal, no ano de 2012, do livro chamado de Livro Vivo, no qual os Kaxinawá registram narrativas sobre saúde, além de diversas plantas e seus usos ${ }^{20}$.

$\begin{array}{llllll}\text { EM TESE } & \text { BELO HORIZONTE } & \text { v. } 19 & \text { N. } 3 & \text { SET.-DE. } 2013 & \text { FARES. Processos tradutórios entre os Kaxinawá }\end{array}$

18. Projeto da O.N.G. homônima (Vídeo nas Aldeias), que instrumentaliza indígenas para fazerem vídeos documentários por conta própria.

19. Núcleo de pesquisa sediado na Fale/UFMG, coordenado por Maria Inês de Almeida, que já publicou mais de 70 livros indígenas.

20. O livro foi iniciativa do paje Mateus Agostinho Manduca e foi escrito predominantemente o uso de uma bula indígena de mais 400 plantas. 
Esta é a primeira experiência tradutória que podemos assinalar. Com toda a dificuldade e impossibilidade na tarefa de traduzir, como nos diz Walter Benjamin no texto "A tarefa do tradutor", Ibã vem traduzindo e nos dando a conhecer diversos cantos e pontos de vistas, perspectivas dos textos Kaxinawá, como este publicado no jornal Guaicurus No 2 do Centro Cultural da UFMG:

Yube nawa aibu, e e e e, e e e e

Yube nawa aibu, e e e e, e e e

Hushu buru namaki, e e e e, e e e e

Pai inakawãtã, e e e e, e e e e

Pae hu amaná, e e e e, e e e e

Xinã metsi sipatã, e e e e, e e e e

Mia hu ashuã, e e e e, e e e e

Tua ibira naitu, e e e e, e e e e

Tawa pai irakã, e e e e, e e e e

Pae ibira naitu, e e e e, e e e e

Sha ibira naitu, e e e e, e e e e

Yube nawa aibu, e e e e, e e e e

Mia hu ashuã, e e e e, e e e e

Pae hu ashuã, e e e e, e e e e

Pae yuwã shutani, e e e e, e e e e

Xinã metsi sipatã, e e e e, e e e e

Nika duku inipe, e e e e, e e e
Jibóia chama o povo branco

Tocos em cima do lombo subindo

No lombo gritando pensamento

Firmando

Você gritando

Vem chegando

Trazendo folha da miração

No lombo vem chegando a força

Chegando

Jibóia povo mulher

Você gritando

No lombo cantando

Pensamento firmeza

Escutando profundo

Força

Jibóia povo mulher

Você gritando

No lombo cantando

Pensamento firmeza

Escutando profundo

Força

Nota-se logo a diferença gráfica do canto Kaxinawá escrito para sua tradução em português. Uma diferença que fica óbvia quando escutamos Ibã cantar em sua língua ${ }^{21}$. Cada "e" escrito em sequência, que ele opta por não colocar na tradução para o português, tem poder rítmico. Assim, o canto
21. Este canto pode ser escutado em soundcloud.com/ccult-ufmg/ cancaokaxinawa 
22. A tese defendida por Charles: Koxuk, a imagem do yãmîy na poética maxakali mostra a relação dos cantos, as imagens e os Yamîy(espíritos). Relação com certa semelhança com os yuxin $e$ yuxibu dos Kaxinawá

23. EISEINSTEIN, $A$ forma do filme, p.122 em língua Huni Kuin se aproxima mais do canto, partitura da oralidade, e já a sua versão para o português se preocupa mais com o sentido do que está sendo cantado.

A sucessão de imagens, como tomadas cinematográficas, pode ser associada à análise que Charles Bicalho faz dos cantos Maxakali ${ }^{22}$. O pesquisador lê esses cantos, que se assemelham em certos aspectos formais e temáticos com os dos Huni Kuin, como montagens cinematográficas, ideogramas narrativos como formulou Eisenstein em sua teoria da montagem: "Montagem é a idéia que nasce da colisão de duas tomadas independentes" e que são apresentadas no decorrer da narrativa em descontinuidade ${ }^{23}$.

Apenas apresentando alguns ícones de forma ritmada - a jibóia, a folha da miração, a jibóia-mulher, a força - da história do Nixi Pae, podemos notar como o canto apresenta de forma sintética a narrativa mítica Kaxinawá. Podemos dizer que este canto/poema possui o que o concretista Décio Pignatari chama de parataxe em oposição ao modo hipotático, mais comumente utilizado por sociedades ditas ocidentais:

a parataxe é a organização por coordenação, e o seu pivô é o conjunto das chamadas conjunções coordenativas; a hipotaxe é a organização por subordinação, que se articula graças às conjunções subordinativas. No Ocidente, domina amplamente a hipotaxe, desde quando os árias, saindo do norte da Índia, falando sânscrito, e caminhando para o ocidente, se transformaram nos gregos, que produziram a fissão nuclear da linguagem e das cabeças, ao criar e desenvolver o sistema predicativo da língua (sujeito/predicado/objeto ou complemento), especialmente quando o verbo ser é aplicado: tal coisa é tal coisa. Daí nasceu a lógica ocidental, que já tomou conta de todo o planeta. ${ }^{24}$

Além deste tipo de tradução interlinguística, noção mais comum quando se trata de tradução, Ibã tem trabalhos em outro tipo de tradução que chamaríamos, conforme tipologia de Roman Jakobson, de intersemiótica. É que, como nos diz Charles Bicalho em sua tese sobre os Maxakali, os rituais indígenas são espetáculos multimídia, pois estão presentes ali toda a arte verbi-voco-visual de que nos falam os poetas concretistas, junção das linguagens verbais, a sonoras e visuais.

É com essa percepção multimidiática que Ibã se preocupa em ampliar o entendimento, as possibilidades gráficas, expressar com mais precisão, através das várias possibilidades artísticas, as mirações de seu povo, as mirações que a ayahuasca e a Jibóia proporcionam para os Kaxinawá. Para isso, Ibã e seu grupo, integram uma associação de artistas chamada Mahku - Movimento dos Artistas Huni Kuin, que tem se dedicado também ao desenho e ao cinema com o intuito de apresentar, sob outras perspectivas, utilizando outros suportes e suas especificidades, a arte, as percepções de mundo e os conhecimentos dos Kaxinawá
24. PIGNATARI, Letras, artes e mídia, p.161

EM TESE

BELO HORIZONTE

v. 19

N. 3

SET.-DEz. 2013 FARES. Processos tradutórios entre os Kaxinawá

P. $137-147$

Tradução e Edição 


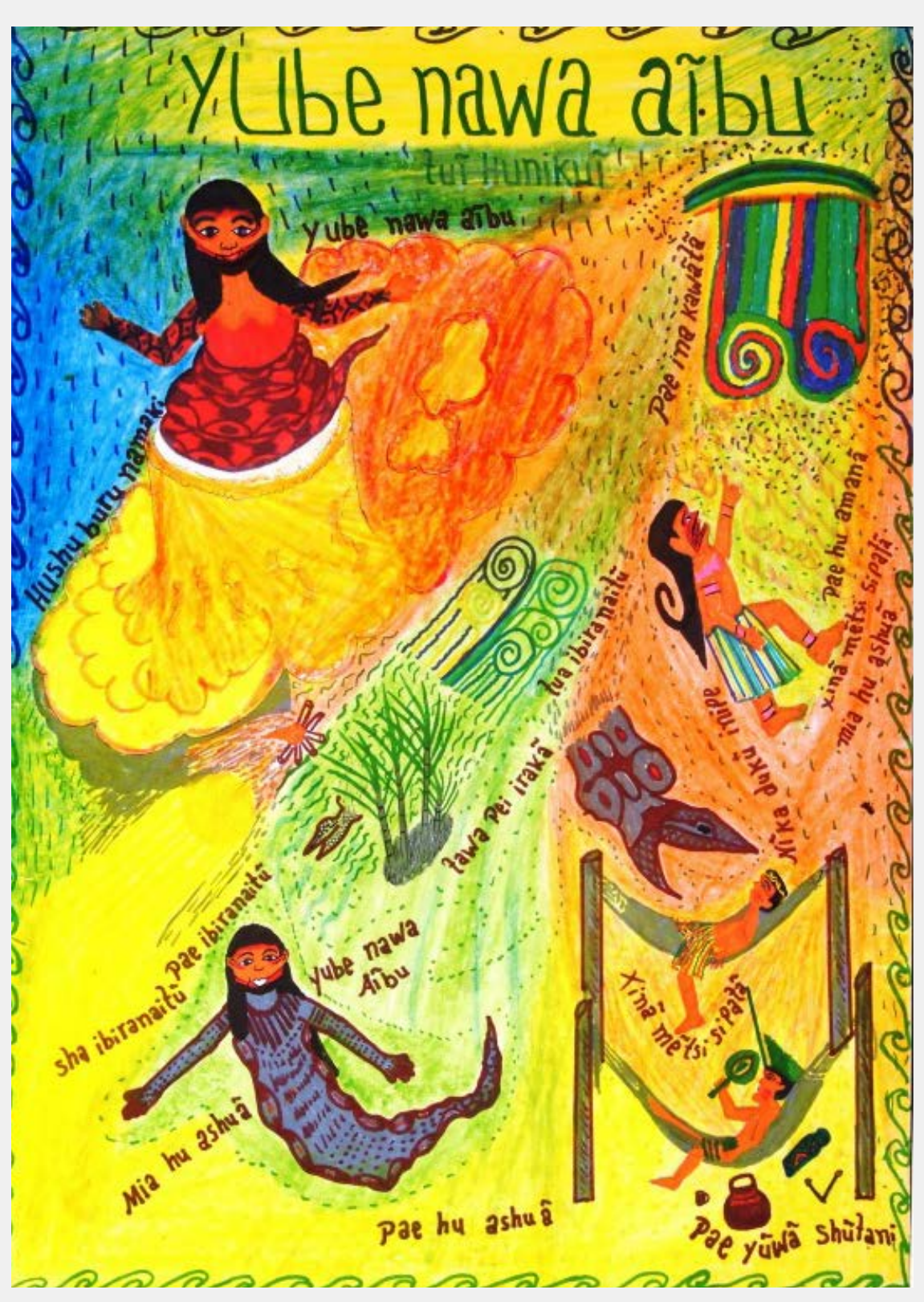

FIGURA 1
No projeto Desenhanho os Espíritos da Floresta - Os cantos de Nixi Pae, o grupo Mahku procurou, junto com os alunos das escolas indígenas Kaxinawá, desenhar as mirações. Eles utilizaram qualquer tipo de material para seus trabalhos: lápis de cor, caneta ou tintas acrílicas. Os “desenhistas” Kaxinawá têm criado muitos quadros, como o que vemos acima, resultando numa grande exposição com o nome do projeto. Neste quadro acima podemos ver claramente a história do Nixi Pae, contada quase como num cartoon, com os mesmos ícones da narrativa figurando lado a lado, remetendo ao modo como o canto também se estrutura, como uma montagem não cronológica e paratática de imagens.

Fruto deste projeto, uma exposição foi criada e realizada na Fundação Cartier na França e também integrou as obras da exposição Mira! - Artes contemporâneas dos povos indígenas ${ }^{25}$, juntamente com outros artistas que também pintam a miração ${ }^{26}$. Como nos explica Ibã, os desenhos são continuações, "são escritos enquanto se escuta os cantos do Nixi Pae”, o que poderíamos nomear de transcriações. Como assinala Haroldo de Campos:

Numa tradução dessa natureza, não se traduz apenas o significado, traduz-se o próprio signo, ou seja, sua fisicalidade, sua materialidade mesma (propriedades sonoras, da imagética visual, enfim tudo aquilo que forma, segundo Charles Morris,
25. Exposição realizada pelo Núcleo Literaterras ocorrida nos meses de julho e setembro no Centro Cultural da UFMG e que irá itinerar pela América do Sul até o fim de 2014.

26. Outros povos também se utilizão da ayahuasca e pintam a partir de suas visões. Dentre eles estavam presente na exposição Mra-Artes Visuais dos povos Conibos. os Shipibo, ShipiboYonibo, Ashaninka, Secoya, 
27. CAMPOS, Metalinguagem - ensaios de teoria e crítica
literária, p. 24. a iconicidade do signo estético, entendido por signo icônico aquele 'que é de certa maneira similar àquilo que ele denota'). O significado, o parâmetro semântico, será apenas e tão-somente a baliza demarcatória do lugar da empresa recriadora. Está-se pois no avesso da chamada tradução literal. ${ }^{27}$

As transcriações são possiblidades tradutórias que não visam propriamente a fidelidade em relação ao original; trata-se de traduções criativas, onde o tradutor é também entendido como um criador, dando a sua contribuição para uma nova forma.

Com a ajuda de parceiros não-indígenas, o grupo Mahku também criou um filme, a partir dos desenhos que têm sido feitos. No filme Espirito da Floresta, mais uma vez podemos perceber a iniciativa de transcriar as visões da ayahuasca numa nova linguagem, utilizando-se de um novo suporte. $\mathrm{O}$ trabalho ali realizado é de tornar as formas mais vivas, mais fluidas, como afirma Ibã, "mais próxima de uma miração". De fato, os Kenes têm geometrias que, desenhadas na pele, produzem efeitos óticos muito mais vibrantes do que no papel. O fato é que com essas ações, Ibã demonstra de forma clara a vontade de poder se aproximar dos recursos tecnológicos e de linguagens, que até pouco tempo não eram de seu domínio, como o cinema, o desenho, a língua portuguesa e

futuramente, a animação para criar novas traduções do mito da jibóia, das Mirações e da ayahuasca, pois cada suporte e cada linguagem dessas proporcionam novas leituras e possibilidades de renovar sua tradição.

Por fim, poderíamos nos perguntar se o processo tradutório constante, que acompanho nestes 7 anos de convívio com Ibã, não seria, ele mesmo, o que produz e de alguma maneira mantém a tradição Kaxinawá para as novas gerações. Tradição não no sentido de um saber dado, uma origem cristalizada no passado, e sim um "furo", como afirma Maria Inês de Almeida em suas 11 teses para a Universidade Indígena ${ }^{28}$ : "A tradição é um furo e não um saber. Por isso ela se confunde com a tradução." Claro, sempre com o estilo próprio e inconfundível dos Kaxinawá. Um rastro ${ }^{29}$, um traço, no sentido cunhado por Derrida na Gramatologia, que se confunde com o grafismo, o canto, a jibóia, a miração, o desenho e, atualmente, o vídeo, e que por ser a tradução uma tarefa impossível, não cessa de significar.

\section{REFERÊNCIAS}

ALMEIDA, Maria Inês de. Desocidentada: experiência literária em terra indígena. Belo Horizonte: Editora UFMG, 2009.

. Maria Inês de (coord). Tabebuia/IPÊ - Índios

Pensamento Educação. Ano 01. Belo Horizonte: Curso de Formação Intercultural de Educadores Indígenas (FIEI/UFMG), 2009
28. AIMEIDA, Tabebuia, p.10

29. Derrida afirma que o rastro é verdadeiramente a origem absoluta do sentido em geral. que vem afirmar, mais uma vez que não há origem absoluta do sentido em geral. O rastro é a diferença que abre o aparec a significação. Articulando o vivo sobre o não vivo em geral, origem de toda rivo eñ geral, da idealidade, ele não é mais ideal que real, não mais inteligive que que real, nấ mais inteligíve quignificação transparente que uma energia opaca e que una energia opaca e nenhum descrevê-lo 
BENJAMIN, W. A tarefa-renuncia do tradutor. In:BRANCO, L. C(org.). A Tarefa do Tradutor, de Walter Benjamin: quatro traduções para o português. Belo Horizonte. Fale/UFMG, 2008.

BICALHO, Charles Antônio de Paula. Koxuk, a imagem do

yâmîy na poética maxakali.Tese apresentada ao Programa de Pós-Graduação em Estudos Literários da Faculdade de Letras UFMG. Belo Horizonte, 2010

\section{CAMPOS, Haroldo de. Metalinguagem - ensaios de teoria} crítica literária. Petrópolis: Vozes, 1970.

CASTRO, Eduardo Viveiros de. Araweté: os deuses canibais. Rio de Janeiro: Jorge Zahar, 1986.

A inconstância da alma selvagem - e outros ensaios de antropologia. 2a ed. São Paulo: Cosac \& Naify, 2006.

CESARINO, Pedro de Niemeyer. Quando a terra deixou de falar: cantos da mitologia Marubo/ organização, tradução e apresentação de Pedro de Niemeter Ceasarino. São Paulo: Editora 34, 2013.

DELEUZE, Gilles. Crítica e clínica. Trad. Peter Pál Pelbart. São Paulo: Ed. 34

DELEUZE, Gilles; GUATTARI, Félix. Mil Platôs: capitalismo e esquizofrenia. vol.4.

Trad. Suely Rolnik. São Paulo: Ed. 34, 1997

Mil Platôs: capitalismo e esquizofrenia, vol.1.Trad. Aurélia Guerra Neto e Célio Pinto Costa. São Paulo: Ed 34, 1995.
DERRIDA, Jacques. Trad. Miriam Schnaiderman e Renato Janini. Gramatologia. São

Paulo: Perspectiva, 1973

EISENSTEIN, S. "O princípio cinematográfico e o ideograma" In Ideograma: lógica poesia linguagem. CAMPOS, Haroldo de. (org.) 3a ed. São Paulo: Ed. da USP, 1994 (p. 149-66).

\section{. "A forma do filme: novos problemas" In: A forma do}

filme. Apresentação, notas e revisão técnica: José Carlos Avellar. Tradução: Teresa Ottoni. Rio de Janeiro: J. Zahar, 2002 (p. 117135)

GUIMARÃES, César. Para tudo isto que um dia chega, para tudo o que poderia um dia chegar ao mundo. In: CASTELLO BRANCO, Lucia; SILVIANO BRANDĀO, Ruth(Orgs). A força da letra: estilo, escrita, representação. Belo Horizonte: Ed. UFMG 2000

JAKOBSON, Roman. Linguística e comunicação. Tradução de Izidoro Blikstein e José Paulo Paes. São Paulo: Cultrix, 1999.

KAXINAWÁ, Ibã. 2007. Huni Meka - Cantos do Nixi Pae. Acre, Comissão Pró Índio.

KAXINAWÁ, Joaquim Paula de Lima et al. 1997. Shenipabu Miyui - História dos Antigos. Acre, Comissão Pró Índio.

KAXINAWÁ. 2006. Doenças e curas do povo Huni Kui. Acre Comissão Pró Índio. 
KAXINAWÁ, Joaquim Paula de Lima. 2002.A arte do kene.Acre, Comissão Pró Índio.

KAXINAWÁ, Isaias Sales. Nixi pae: 0 espírito da floresta. Rio Branco: Comissão Pró- Indio do Acre, 2006.

KAXINAWÁ, Joaquim de. Nuku kene xarabu. Rio Branco: CAPEMA, 2006.

LAGROU, Els. Fluidez da forma: arte, alteridade e agência em uma sociedade amazônica (Kaxinawá, Acre). Rio de Janeiro: Topbooks, 2007.

MATEUS, Agostinho Manduca. Huna Hiwea, O Livro Vivo/ Agostinho Manduca Mateus, organizador. Belo Horizonte: Literaterras/ Faculdade de Letras UFMG, 2012.

PIGNATARI, Décio. Letras, artes, mídia. São Paulo: Globo, 1995.

Informação/Linguagem/Comunicação. SP: Ateliê Editorial, 2002. 